\title{
DEVELOPMENT OF "CONTENT-FOCUSED ACCESSIBILITY” E-LEARNING MATERIAL FOR ENGLISH LEARNING TARGETING VISUALLY IMPAIRED UNIVERSITY STUDENTS
}

\author{
Chikako Ota \\ Division of Research on Support for the Hearing and Visually Impaired, \\ Research and Support Center on Higher Education for the Hearing and Visually Impaired, \\ National University Corporation Tsukuba University of Technology (Japan)
}

\begin{abstract}
Students with visual impairment use media conversion (e.g., enlarged characters and braille) and ICT environments (e.g., sounds and PC screen magnification) to learn English. However, there are very few English learning materials in braille, and magnification-capable and digital materials for higher education are not commercially available. Although many publishers produce online English learning materials, many do not allow screen magnification and text-to-speech function. Therefore, students with visual impairment need to create braille versions of and/or text data for such materials. However, satisfying such requests is time consuming, which may cause students to lose important opportunities or motivation A self-learning environment for students with visual impairment to study English has not been completely developed.

The author found that, in many cases, only these "technical accessibility" of learning materials is insufficient for students with visual impairment to respond to questions depending on question patterns. Due to the absence of useable leaning materials, the English skills of many visually impaired students are surprisingly low. Nonetheless, university students require basic English skills. Hence, this study presents original attempts to modify the organization of questions for self-learning English grammar books. The author refers to this material as original e-learning "content-focused accessibility" material.

The author's students with visual impairment studied this material and provided feedback from the following perspectives: 1) effectiveness of the material, 2) suggestions to improve the material, and 3) improvement of activeness for learning English after studying the material. Further, the author analyzed the students' grades before and after studying the material.

The study revealed four interesting results: 1) Approximately $90 \%$ of the students with severe visual impairment found "content-focused accessibility" material very useful. 2) Those with severe visual impairment provided both positive feedback on and suggestions for improvement of the material. 3) Approximately $90 \%$ of the students with severe visual impairment significantly improved their automony for English learning after studying this material. 4) Finally, 80\% of the students with severe visual impairment who studied this material improved their grades. Furthermore, $100 \%$ of them answered that their automomy improved after studying the material. These results demonstrate the effectiveness of "content-focused" accessibility material in the self-learning of students with severe visual impairment.
\end{abstract}

Keywords: Visual impairment, “content-focused accessibility”, e-learning, students' engagement in English self-learning.

\section{Introduction}

Students with visual impairment use media conversion (e.g., enlarged characters and Braille) and information and communications technology (ICT) environments (e.g., sounds and personal computer (PC) screen magnification) to learn English. However, there are very few English learning materials in braille, and magnification-capable and digital materials for higher education are not commercially available. Although many publishers produce online English learning materials, many do not allow screen magnification and text-to-speech function. Therefore, students with visual impairment need to create braille versions of and/or text data for such materials. However, satisfying such requests is time consuming, which may cause students to lose important opportunities or motivation. A self-learning environment for students with visual impairment to study English has not been completely developed.

In addition, some students are at a loss due to the absence of learning materials, and others have difficulty keeping up with classes due to their lack of skills in English. This occurs because students' visual impairment varies a lot, and their English learning backgrounds also vary a lot depending on when they were first impacted by visual impairment. In this aspect, the author believes it is critical to provide conducive English learning environments for visually impaired students. 
In this study, the author calls media conversion learning materials as well as ICT environments "technical accessibility to information". In many cases, it is remarkably difficult for students with visual impairment to utilize only "technical accessibility to information" in English learning, depending on the pattern of question (e.g., multiple choice, fill-in-the-blanks, etc.) as shown in previous studies. Nonetheless, a number of students require foundations to be established for a basic knowledge of general English. In addition, as some students aspire to enter graduate school, teacher-training courses of other universities, or take English certification examinations (STEP Test, TOEIC, etc.) for gaining employment, there is a substantial demand for the acquisition of basic English skills.

This study presents pioneering attempts to modify original learning materials regarding the various patterns of questions. This is what the author calls "content-focused accessibility to information", which enables visually impaired students to study English more efficiently.

\section{Design of the Study}

\subsection{General modification attempts}

Attempts for Students with Severe Visual Impairments (blindness, almost complete blindness / severe low vision, extremely narrowed vision field)

As the system could not be designed for mouse users, it uses processes to operate buttons using sounds and select choices from the provided answers through keyboard operation. In addition, both sound and braille character outputs were used concurrently.

Attempts for the Rest of the Students (low vision, narrowed vision field, central scotoma, arcuate scotoma, night blindness, light aversion, and other types of visual impairment) similar features.

The system enabled changes in character sizes, layouts, background colors, character colors, and

\subsection{Attempts to modify the learning Material}

This study uses Moodle, the open-source software package, as the basis of the e-learning system to create of web pages on the Internet. Various methods were added to "technical accessibility to information" and learning materials to ensure ease of use by students with visual impairment.

The textbooks provide the foundation of basic English grammar for junior high school and high school students. Questions were roughly divided into three types: (i) fill-in-the-blanks, (ii) multiple choice, and (iii) writing tasks.

(i) Fill-in-the-blank Questions

-Original Question

"Fill in the blanks in English sentences with a suitable word from among the choices within the parentheses."

I saw at the station yesterday. (she, her, hers)

The original format showed entire sentences, including the blanks, followed by the answer choices. Students had to memorize all the choices, before returning to the blank space to provide an answer from the options. If students could not remember even a single word, they would have to go back to view the choices again. This system was inefficient.

-Situation after Improvement via the System

Figure 1. Screen for Fill-in-the-blank.

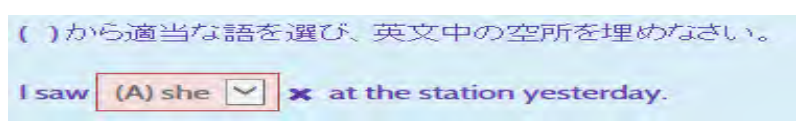

A pull-down menu was provided to indicate choices for the blank space. In this system, students can answer and fill in the blank when they read or listen to the sentence, without having to return to the options after reading or listening to the entire sentence. Using a PC-Talker, students can listen to questions and answer choices in English and explanations in Japanese.

(ii) Multiple Choice Questions

-Original Question

"Choose the correct usage of present tense from (1) (3) and answer the number."

[1)present status (2)present repetitive motion (3)general fact or truth]

1) Mr. Smith understands Japanese. ( )

2) Water boils at $100^{\circ} \mathrm{C}$.

3) My brother plays soccer with his friends on Sundays. ( )

4) Lisa often talks to her Japanese friend on the phone. ( ) 
5) Mary resembles her mother very much.

In the original format, students had to go back and forth between the question and answer choices. Alternatively, they had to remember all the answer choices. This system was inefficient.

-Situation after Improvement via the System

The format was changed into one which showed all the choices for each question. The format also adopted a new method to answer questions by pushing a radio button. In addition, the underlines were changed into a readable symbol "【】” so that students with severe visual impairment could listen via the text-to-speech screen reader function.

"Choose the correct usage of present tense from (1) (3) and answer the number."

1) Mr. Smith【understands】Japanese.

opresent status

opresent repetitive motion

ogeneral fact or truth
2) Water【boils】at $100^{\circ} \mathrm{C}$.

opresent status

opresent repetitive motion

ogeneral fact or truth

(iii) Writing Task Questions

-Original Question

"Encircle the modifier in the underlined portion."

The red car parked under that tree belongs to my brother.

-Situation after Improvement via the System

Students with severe visual impairments who were unable to use a mouse could not encircle specific words or phrases on a PC. Therefore, the word "underlined" was changed into a readable symbol "【】", and the phrase "underlined portion" was altered to "portion enclosed in "【】'." The old format was changed into one in which the modifier related to the underlined portion was described by learners as follows:

The red car【parked under that tree】belongs to my brother.

Figure 2. Screen for Writing Task Questions.

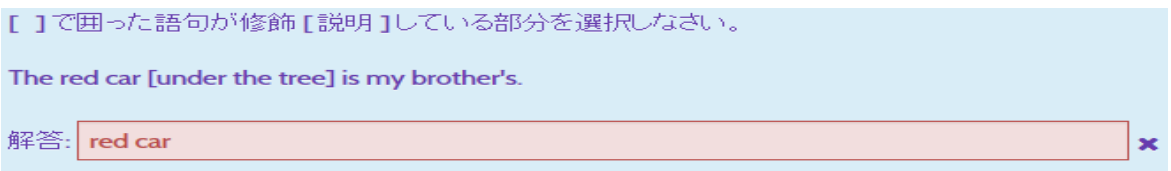

\section{Discussion}

\subsection{Assessment for "content-focused accessibility" e-learning materials}

The author conducted an assessment of "content-focused accessibility" of e-learning materials to confirm the educational effect of the materials for visually impaired students. The author gave 25 first-year students with visual impairment an assignment to study using "content-focused accessibility" material, and obtained their feedback from the following perspectives: 1) effectiveness of the material, 2) suggestions to improve/revise the material, and 3) development of autonomy for learning English after studying the material. Further, the author analyzed the students' grades before (a placement test) and after (the final examination) studying the material.

Students can be classified into five categories as follows (total number respectively): speakers)

1) users of braille (6 students: 5 males and 1 female, ages from 18-24, all Japanese native

2) users of text-to-speech function (6 students: 5 males and 1 female, ages from 18-24, all Japanese native speakers)

3) users with almost complete loss of visual field (4 students: 3 males and 1 female, ages from 18-38, all Japanese native speakers)

4) other users (low vision, narrowed visual field, central scotoma, night blindness, light aversion) (18students: 16 males and 2 females, ages from 18-38, all Japanese native speakers)

5) users who can read printed learning material without major difficulties ( 5 students: 3 males and 2 females, ages from 18-19, all Japanese native speakers)

The students' feedback reported above revealed four interesting results: 
Figure 3. Effectiveness of "Content-Focused Accessibility” Material.

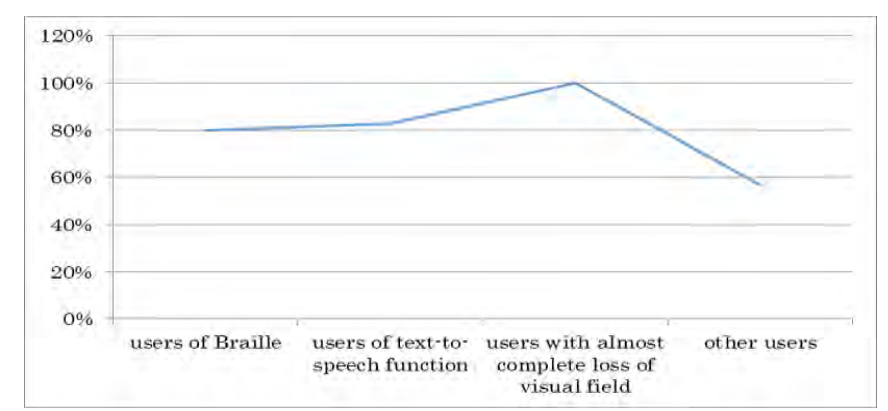

1) Approximately 92\% (12/13 students) students with severe visual impairments (blindness, almost complete blindness, users of text-to-speech functions and/or braille, almost complete loss of visual field) found "content-focused accessibility" material very useful (Figure 3).

2) Those with severe visual impairment provided both positive feedback and more detailed suggestions for improvement/revision of the material.

Figure 4. Development of Autonomy for Learning English after Studying “Content-Focused Accessibility”Material.

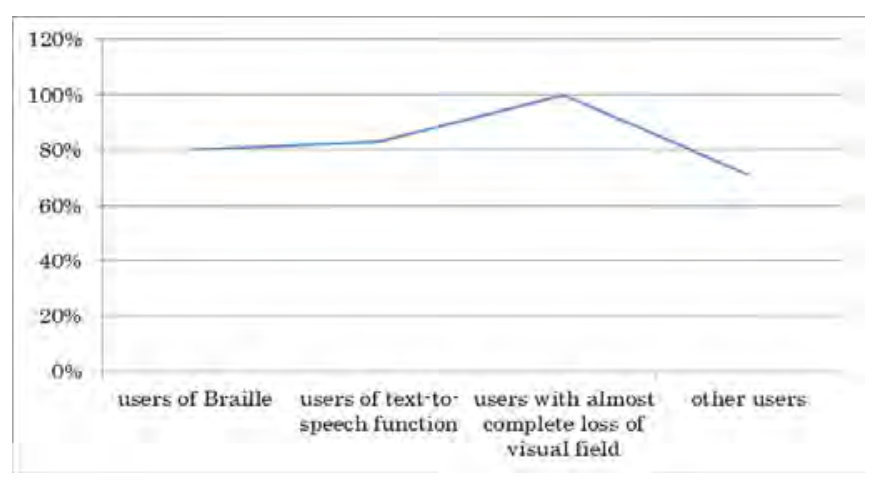

3) Approximately $92 \%$ (12/13 students) of the students with severe visual impairment significantly developed their autonomy for English learning after studying material developed by this system (Figure 4). material.

Furthermore, 100\% (9/9 students) answered that their autonomy developed after studying the

Figure 5. Improvement of Students' Grades After Studying the “Content-Focused Accessibility”Material.

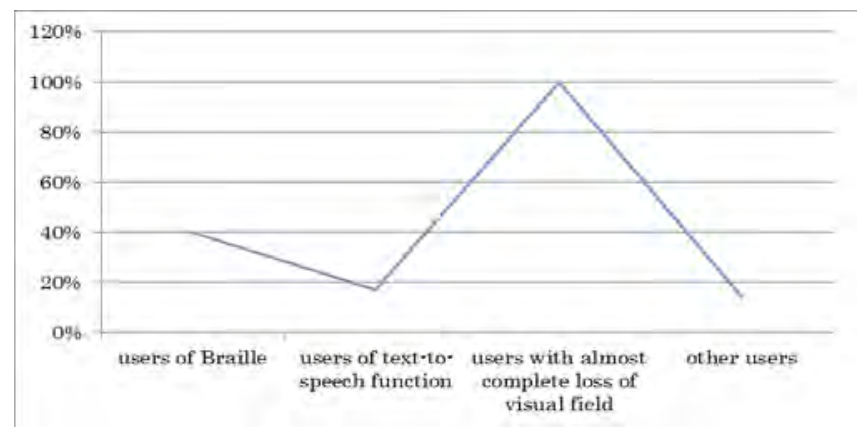

4) About 32\% (8/25 students) of the entire group and about 73\% (8/11 students) of those with severe visual impairment improved their grades at the final examination of the first semester (Figure 5). Finally, about 44\% (4/9 students) students with severe visual impairment at low-to-middle English proficiency levels improved their grades at the end of the first semester after studying material developed by this system. $100 \%$ (13/13 students) of those with severe visual impairment answered that their autonomy improved after studying the material.

\subsection{Students' engaged learning}

Based on students' feedback, the author finds that most visually impaired students are actively engaged in self-learning based on their self-analysis. This finding is significant as it provides new insights that will help facilitate visually impaired students' self-learning. 
Students with visual impairment tend not to have opportunities to review their present English skills since they have to make a lot of efforts to keep up with daily tasks (e.g., required English classes). The author found it significant that visually impaired students themselves analyzed their present English skills and decided which "content-focused accessibility" material they needed, without guidance, help, or suggestions from anyone else. Some students consulted the author regarding which "content-focused accessibility" material to choose based on their English skills. They analyzed their weak points and future needs very precisely. Finally, one student chose "content-focused accessibility" material that was different from the ones recommended by the author. Hence, the author regards it meaningful to develop "content-focused accessibility" as this might inspire students with visual impairment to engage in self-learning, something that is often said to be difficult.

\section{Conclusion}

These results demonstrate the effectiveness of "content-focused accessibility" material in the self-learning activities of students, especially those with severe visual impairment. The findings are convincing, since students with severe visual impairment need more accessibility to information than those with relatively lighter visual impairment. An additional important factor to consider in students' learning environments is whether their visual impairment is congenital or acquired. Students whose visual impairment is both severe and acquired recently have the biggest difficulty ( 2 students). Their feedback had a significant importance in this study.

Those with severe visual impairment provided both a lot of positive feedback together with more detailed suggestions for improvement/revision of the material. This is also convincing since they experienced the effectiveness of "content-focused accessibility" material more and showed significant improvement in autonomy for learning English after studying material developed by this system.

\section{Proposals for further studies}

As indicated by the students' comments, this system suffers from some issues that impede accessibility for students with all kinds of visual impairment. These issues are as follows:

1) As some students could not grasp the whole screen and navigation on the edge of it when it was widened, they occasionally could not understand which question they were working on.

2) Some students with visual impairment face difficulty in seeing ordinal color contrast. Most of them typically use a black-white inverted screen.

3) In Writing Task questions, it is difficult for users of text-to-speech function and those with severe low vision to notice half-width space. Some questions request this space as the correct answer, which becomes a factor influencing learning motivation.

The author is currently working on addressing the problems mentioned abpve. Points 2) and 3) can easily be dealt with by the author, by changing the system. Furthermore, these improvements/revisions would meet the needs of both those with severe visual impairment as well as those with low vision conditions, which means that the improved/revised material applies to all kinds of visual impairments. As for point 1), careful improvement/revision would be required to address all kinds of visual impairment.

In the near future,

1) Work will continue on the development of a new version of the present system using "content-focused accessibility to information" for all kinds of visual impairment that will address the problems found in the present system.

2) This e-learning material is limited to the university due to the licensing agreement. It is hoped that possibilities will be provided that allow students with visual impairment who are learning at institutions of higher education throughout Japan to independently undertake English studies in response to reasonably accommodate all disabled students.

\section{References}

Aoki, K. (2009). Effective Use of Text-to-Speech Technology for Japanese Learners of English. NTUT Education of Disabilities, $7: 1-10$.

Aoki, K., Katoh, H., Kobayashi, M., \& Kondo, K. (2003). Are Visually Impaired Students Slow Readers? What Reading Support Software Can Do for Them? Eurocall 2003, 39.

https://docs.moodle.org/36/en/URL_resource (23 July 2018). 1/8/2009.

Kashdan, S., Robby B., \& Cecilia E. W. (2005). Teaching English as a New Language to Visually Impaired and Blind ESL Students: Problems and Possibilities. American Foundation for the Blind.

Saito, K. (2009a). Bariafuri komyunikeishon wo mezasu daigakusei no tame no Eigokyoiku kyozai [English Teaching Software for University Students Aiming at Barrier-free Communication]. Journal of Japan Association for College and University Education, 31(1), 154-161.

Saito, K. (2009b). The Development of Barrier-free English Learning Software. Journal of Social Policy and Social Work, 55:39-57. 